\title{
Life activity, disease acceptance and quality of life in patients treated with renal replacement therapy since childhood
}

\author{
Dominika Adamczuk ${ }^{A-D}$, Maria Roszkowska-Blaim ${ }^{A, C-E}$, Beata Leszczyńska ${ }^{A, B, D, E}$, Małgorzata Pańczyk-Tomaszewska ${ }^{A, D-F}$ \\ Department of Pediatrics and Nephrology, Medical University of Warsaw, Poland \\ A - research concept and design; $B$ - collection and/or assembly of data; $C$ - data analysis and interpretation; \\ $D$ - writing the article; $E$ - critical revision of the article; $F$ - final approval of the article
}

Address for correspondence

Dominika Adamczuk

E-mail:d.adamczuk@gmail.com

Funding sources

None declared

Conflict of interest

None declared

Received on April 10, 2016

Reviewed on September 12, 2016

Accepted on August 8, 2018

Published online on April 5, 2019

Cite as

Adamczuk D, Roszkowska-Blaim M, Leszczyńska B,

Pańczyk-Tomaszewska M. Life activity, disease acceptance and quality of life in patients treated with renal replacement therapy since childhood. Adv Clin Exp Med. 2019;28(7):

871-878. doi:10.17219/acem/94070

DOI

10.17219/acem/94070

Copyright

Copyright by Author(s)

This is an article distributed under the terms of the

Creative Commons Attribution Non-Commercial License

(http://creativecommons.org/licenses/by-nc-nd/4.0/)

\begin{abstract}
Background. Advances in the treatment of chronic kidney disease (CKD) resulted in expanding therapy goals from simple prolongation of life to a return to normal social functioning and having an active and satisfactory life after reaching adulthood.

Objectives. The aim of the study was to evaluate life activity, disease acceptance (DA) and quality of life (QOL) in patients with end-stage renal disease (ESRD) treated with renal replacement therapy (RRT) since childhood.

Material and methods. We surveyed 117 patients aged $\geq 16$ years on RRT since childhood. The control group included 25 healthy subjects. We used questionnaires that included a sociodemographic questionnaire (questions regarding education, work, family, and offspring), Acceptance of Illness Scale (AIS), Satisfaction With Life Scale, and Kidney Disease Quality of Life (KDQOL).

Results. A completed survey was returned by 45 respondents aged $27.16 \pm 6.78$ years, among whom $82.2 \%$ had a transplanted kidney and 17.8\% were on hemodialysis (HD). Higher education was reported by $18.18 \%$ of respondents, secondary and primary by $63.64 \%$ and $18.18 \%$, respectively. Employment was reported by $46.67 \%$ of the respondents. A family was started by $35 \%$ of women and $4 \%$ of men. Good DA was found in $28.9 \%$ of the respondents. Satisfaction with life was lower in the study group compared to the control group. We found statistically significant correlations between the age when the kidney disease was diagnosed and satisfaction with life $(r=0.33)$, and between the time since the last change of RRT modality and emotional well-being $(r=0.34)$. The number of kidney transplantations correlated negatively with emotional component of QOL ( $r=-0.66)$ and emotional well-being $(r=-0.73)$.
\end{abstract}

Conclusions. Patients treated with RRT were quite well adapted to their chronic disease but showed less ability to live independently. Young age at the diagnosis of kidney disease, loss of kidney transplant and living on social security benefit had a negative effect on their emotional well-being.

Key words: quality of life, dialysis, end stage renal disease, kidney transplant, childhood 


\section{Introduction}

Chronic diseases affect the functioning and mental status of patients. Patients with somatic disease experience many negative emotions and limitations caused by the disease, and the prolongation of life does not necessarily translate to an improvement in quality of life (QOL), which is considered a prognostic factor for patient morbidity and mortality. ${ }^{1-3}$ Advances in the treatment of chronic kidney disease (CKD) resulted in expanding therapy goals from simple prolongation of life to a return to normal social functioning and having an active and satisfactory life after reaching adulthood. It is also known that patients treated with renal replacement therapy (RRT) since childhood have a feeling of dependence on other persons, isolation from their family and peers, and an awareness of worse life conditions compared to healthy people, which may lead to reduced QOL. ${ }^{4-6}$

The aim of the study was to evaluate life activity, disease acceptance (DA), satisfaction with life, and QOL in patients with end-stage renal disease (ESRD) treated with RRT since childhood.

\section{Material and methods}

We studied 117 patients aged $\geq 16$ years who first received RRT due to ESRD as children in the Department of Pediatric Nephrology at the Medical University of Warsaw, Poland, in 1973-2007. Information on the disease course and RRT methods used during childhood were retrieved from medical records. Diagnosis of CKD was defined as decrease of glomerular filtration rate below $60 \mathrm{~mL} / \mathrm{min} / 1.73 \mathrm{~m}^{2}$ or presence of permanent kidney damage (pathologic abnormalities or markers of damage in blood and urine tests, or imaging studies abnormalities).

The control group included 25 healthy adults (13 women and 12 men) at the mean age of $27 \pm 7.36$ years, ageand gender-matched to the study group. Clinical data in the control group was collected using an interview.

The study was a cross-sectional survey performed using a set of questionnaires and scales:

1) a sociodemographic questionnaire that included information on further RRT after transition from pediatric to adult care, education, place of residence, professional status, and family situation; and

2) professional psychometric tools:

a) Acceptance of Illness Scale (AIS) by Felton et al. The studied subject evaluates whether negative disease consequences such as lack of self-reliance, feeling of dependence on others, reduced self-esteem, and disease-related limitations are present in his/her life. Overall score (8-40) corresponds to the degree of DA. Low disease acceptance was defined as score $\leq 23$, moderate DA as score $24-36$ and high DA as score $\geq 37^{\text {? }}$.

b) Satisfaction With Life Scale (SWLS) by Diener et al. Overall score ranges from 5 to 35 . Scores 5-17 indicate low satisfaction with life, scores $18-23$ indicate moderate satisfaction with life and scores 24-35 indicate high satisfaction with life. ${ }^{7}$

c) Kidney Disease Quality of Life - Short Form (KDQOL - $\mathrm{SF}^{\mathrm{TM}}$ ) by the RAND Group (University of Arizona, Tucson, USA) in Polish translation. ${ }^{8}$ Kidney Disease Quality of Life is used to evaluate QOL in subjects receiving RRT and consists of 2 parts: a generic questionnaire (SF-36 form) to evaluate overall health related quality of life (HRQOL), and a specific questionnaire to evaluate QOL related to kidney disease. For each item, scores range from 0 to 100 , where 0 indicates a negative answer and poor QOL, and 100 indicates good QOL.

All procedures performed in studies involving human participants were in accordance with the ethical standards of the institutional and/or national research committee and with the 1964 Helsinki Declaration and its later amendments or comparable ethical standards. The study was approved by the ethics committee at the Medical University of Warsaw, Poland. Informed consent was obtained from all individual participants included in the study.

\section{Statistical analysis}

Normal distribution of variables was examined using the Shapiro-Wilk and Lilliefors tests. Normally distributed data is shown as mean values \pm standard deviations (SD), and non-normally distributed data is shown as medians and ranges. Significance of differences in the mean values between normally distributed independent or interrelated groups is evaluated using the Student's t-test for independent or paired samples, respectively. Non-normally distributed data was compared using the Mann-Whitney U test for independent sample or the Wilcoxon test for paired samples.

The Pearson's $X^{2}$ test was used to compare frequencies between groups. Correlations between variables were evaluated using linear regression analysis. A value of $\mathrm{p}<0.05$ was considered statistically significant.

Statistical analyses were performed using the STATISTICA v. 9.0 software (StatSoft Inc., Tulsa, USA).

\section{Results}

Among 117 patients qualifying for the study (mean age $29.50 \pm 7.81$ years), response was obtained from 71 patients $(60.68 \%)$, including the consent for participation in the study and returned questionnaires from 45 respondents ( 20 women and 25 men) at the mean age of $27.16 \pm 6.78$ years and information about patient death from the families of 26 patients. The most common causes of ESRD were congenital anomalies of the urinary tract (58\%) and glomerulonephritides (31\%).

Data was analyzed in 2 observation periods depending on the date of RRT initiation: group A with RRT initiated 
in 1973-1992 and group B with RRT initiated in 19932007. Clinical characteristics of the study group are shown in Table 1. We found no significant differences between groups $\mathrm{A}$ and $\mathrm{B}$ in regard to the mean age at the time of the diagnosis of CKD and initiation of RRT. Men were significantly younger than women at the diagnosis of CKD $(4.3 \pm 5.0$ vs $7.7 \pm 4.8$ years; $p<0.05)$ but gender had no effect on the age when RRT was initiated. The mean total duration of RRT was $15.6 \pm 6.6$ years, including $4.2 \pm 2.9$ years under pediatric care and $11.5 \pm 7.0$ years under adult care. During childhood, peritoneal dialysis (PD) was used in $66.7 \%$ of the patients for the mean duration of $3.3 \pm 2.4$ years and hemodialysis (HD) was used in $68.9 \%$ of the patients for the mean duration of $2.8 \pm 2.7$ years. Kidney transplantation during childhood was performed in $73.3 \%$ of the patients. Overall, during RRT, kidney transplantation was performed in $97.8 \%$ of the patients, including $24 \%$ of the patients who received kidney transplant twice and $4.5 \%$ of the patients who received it 3 times.
During adulthood, HD was used in $80 \%$ of the patients for the mean duration of $6.1 \pm 4.9$ years and PD in $16 \%$ of the patients for the mean duration of $3.3 \pm 3.3$ years. At the time of study, $82.2 \%$ of the respondents had a kidney transplant, including $73.9 \%$ in group A and $90.9 \%$ in group B, a non-significant difference. Hemodialysis was used in $17.8 \%$ of the respondents, including $26.1 \%$ in group $\mathrm{A}$ and $9.1 \%$ in group $\mathrm{B}$.

Demographic and current life activity data is shown in Table 2. Urban place of residence was reported by $71 \%$ of the respondents, significantly more commonly women $(\mathrm{p}<0.05)$. No significant differences in the level of education were seen in relation to gender and the period of RRT initiation. Among 30 patients who finished their education, $57 \%$ had no trained profession (finished primary school or general high school), significantly more commonly among those in whom RRT was initiated in 1973-1992. Lack of trained profession was observed more commonly in men (45.83\%) than in women (30\%), but

Table 1. Clinical characteristics of the study group

\begin{tabular}{|c|c|c|c|c|c|c|}
\hline $\begin{array}{c}\text { Parameters } \\
\text { [years] }\end{array}$ & $\begin{array}{c}\text { Total } \\
\mathrm{n}=45, \text { mean } \pm \mathrm{SD} \\
(\text { range })\end{array}$ & $\begin{array}{c}\text { Group } A \\
1973-1992 \\
\mathrm{n}=23, \text { mean } \pm \mathrm{SD} \\
(\text { range) }\end{array}$ & $\begin{array}{c}\text { Group B } \\
1993-2007 \\
\mathrm{n}=22, \text { mean } \pm \mathrm{SD} \\
\text { (range) }\end{array}$ & 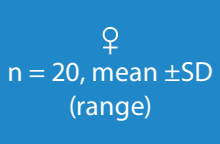 & $\begin{array}{c}\widehat{\delta} \\
\mathrm{n}=25, \text { mean } \\
(\text { range })\end{array}$ & $p$-value \\
\hline Age & $\begin{array}{c}27.2 \pm 6.8 \\
(16.3-45.1)\end{array}$ & $\begin{array}{l}30.9 \pm 6.6^{1} \\
(18.7-45.1)\end{array}$ & $\begin{array}{l}23.2 \pm 4.4^{1} \\
(16.3-29.5)\end{array}$ & $\begin{array}{c}25.2 \pm 4.9 \\
(16.3-32.4)\end{array}$ & $\begin{array}{c}28.7 \pm 7.8 \\
(18.3-45.1)\end{array}$ & $\begin{array}{c}1 p<0.0001 \\
\text { A vs B }\end{array}$ \\
\hline $\begin{array}{l}\text { Age at CKD } \\
\text { diagnosis }\end{array}$ & $\begin{array}{c}5.9 \pm 5.2 \\
(0.0-15.6)\end{array}$ & $\begin{array}{c}5.4 \pm 4.4 \\
(0.4-14.3)\end{array}$ & $\begin{array}{c}6.3 \pm 6.0 \\
(0.0-15.6)\end{array}$ & $\begin{array}{l}7.7 \pm 4.8^{2} \\
(0.6-15.3)\end{array}$ & $\begin{array}{l}4.3 \pm 5.0^{2} \\
(0.0-15.3)\end{array}$ & $\begin{array}{c}2 p<0.05 \\
\quad \text { Q vs O' }\end{array}$ \\
\hline $\begin{array}{l}\text { Age at start } \\
\text { of RRT }\end{array}$ & $\begin{array}{l}11.5 \pm 4.4 \\
(2.1-20.2)\end{array}$ & $\begin{array}{l}10.4 \pm 4.5 \\
(2.1-20.2)\end{array}$ & $\begin{array}{c}12.6 \pm 4.1 \\
(3.9-18.5)\end{array}$ & $\begin{array}{c}11.5 \pm 4.0 \\
(3.6-18.5)\end{array}$ & $\begin{array}{l}11.6 \pm 4.9 \\
(2.1-20.2)\end{array}$ & NS \\
\hline $\begin{array}{l}\text { Total time } \\
\text { of RRT }\end{array}$ & $\begin{array}{c}15.6 \pm 6.6 \\
(3.0-30.8)\end{array}$ & $\begin{array}{c}20.4 \pm 4.6^{3} \\
(15.9-30.8)\end{array}$ & $\begin{array}{l}10.6 \pm 4.2^{3} \\
(3.0-16.2)\end{array}$ & $\begin{array}{c}13.8 \pm 6.3 \\
(3.0-25.8)\end{array}$ & $\begin{array}{c}17.0 \pm 6.6 \\
(4.5-30.8)\end{array}$ & $\begin{array}{c}{ }^{3} p<0.0001 \\
A \text { vs } B\end{array}$ \\
\hline
\end{tabular}

CKD - chronic kidney disease; RRT - renal replacement therapy.

Table 2. Demographic data of subjects from the study group

\begin{tabular}{|c|c|c|c|c|c|c|}
\hline Parameters & $\begin{array}{l}\text { Respondents } \\
n=45[\%]\end{array}$ & $\begin{array}{c}\text { Group A } \\
n=23 \\
1973-1992[\%]\end{array}$ & $\begin{array}{c}\text { Group B } \\
n=22 \\
1993-2007[\%]\end{array}$ & $\mathrm{n}=\stackrel{\stackrel{+}{20}[\%]}{[}$ & 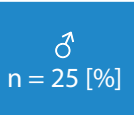 & $p$-value \\
\hline $\begin{array}{l}\text { Place of residency } \\
\text { 1. rural area } \\
\text { 2. urban area }\end{array}$ & $\begin{array}{l}28.89 \\
71.11\end{array}$ & $\begin{array}{l}34.78 \\
65.22\end{array}$ & $\begin{array}{l}22.73 \\
77.27\end{array}$ & $\begin{array}{l}15.00^{1} \\
85.00^{2}\end{array}$ & $\begin{array}{l}40.0^{1} \\
60.0^{2}\end{array}$ & $1,2 p<0.05$ o v $\sigma^{*}$ \\
\hline $\begin{array}{l}\text { Education } \\
\text { 1. higher } \\
\text { 2. secondary } \\
\text { 3. primary }\end{array}$ & $\begin{array}{l}18.18^{4} \\
63.64^{4} \\
18.18^{4}\end{array}$ & $\begin{array}{l}18.18 \\
59.09 \\
22.73\end{array}$ & $\begin{array}{l}18.18 \\
68.18 \\
13.64\end{array}$ & $\begin{array}{l}30.00 \\
60.00 \\
10.00\end{array}$ & $\begin{array}{l}8.33 \\
66.67 \\
25.00\end{array}$ & NS \\
\hline $\begin{array}{l}\text { Trained profession } \\
\text { 1. yes } \\
\text { 2. no } \\
\text { 3. still learning }\end{array}$ & $\begin{array}{l}29.55 \\
38.64 \\
31.82\end{array}$ & $\begin{array}{l}31.82 \\
54.55^{3} \\
13.64^{4}\end{array}$ & $\begin{array}{l}27.27 \\
22.73^{3} \\
50.00^{4}\end{array}$ & $\begin{array}{l}30.00 \\
30.00 \\
40.00\end{array}$ & $\begin{array}{l}29.17 \\
45.83 \\
25.00\end{array}$ & $\begin{array}{c}3,4 p<0.05 \\
A \text { vs } B\end{array}$ \\
\hline $\begin{array}{l}\text { Employment } \\
\text { 1. yes } \\
\text { 2. no } \\
\text { 3. no but still learning }\end{array}$ & $\begin{array}{l}46.67 \\
33.33 \\
20.00\end{array}$ & $\begin{array}{c}47.83 \\
43.47 \\
8.70\end{array}$ & $\begin{array}{l}45.45 \\
22.73 \\
31.82\end{array}$ & $\begin{array}{l}50.00 \\
25.00 \\
25.00\end{array}$ & $\begin{array}{l}44.00 \\
40.00 \\
16.00\end{array}$ & NS \\
\hline Own family & 17.78 & 26.09 & 9.09 & $35.00^{7}$ & $4.00^{7}$ & $\begin{array}{c}{ }^{7} p<0.05 \\
\text { q vs o" }\end{array}$ \\
\hline Children & 9.89 & 8.70 & 9.09 & 15.00 & 4.00 & NS \\
\hline
\end{tabular}


Table 3. Results of Satisfaction with Life Scale in study and control group

\begin{tabular}{|c|c|c|c|c|}
\hline \multirow{2}{*}{$\begin{array}{l}\text { Examined } \\
\text { groups }\end{array}$} & \multirow{2}{*}{$\begin{array}{c}\text { Total scores, } \\
\text { mean } \pm \mathrm{SD}\end{array}$} & \multicolumn{3}{|c|}{ Satisfaction with life [\%] } \\
\hline & & poor & average & good \\
\hline \multicolumn{5}{|c|}{ Study group } \\
\hline Total & $19.56 \pm 5.95^{1}$ & $46.67^{2}$ & 22.22 & 31.11 \\
\hline Group A & $18.48 \pm 5.32$ & 56.52 & 26.09 & $17.39^{4}$ \\
\hline Group B & $20.68 \pm 6.47$ & 36.36 & 18.18 & $50.00^{4}$ \\
\hline 우 & $20.20 \pm 6.69^{3}$ & 40.00 & 20.00 & 40.00 \\
\hline$\sigma^{*}$ & $19.04 \pm 5.37$ & 52.00 & 24.00 & 24.00 \\
\hline Tx & $19.65 \pm 6.28$ & 48.65 & 16.22 & 35.14 \\
\hline HD & $19.13 \pm 4.39$ & 37.50 & 50.00 & 12.50 \\
\hline \multicolumn{5}{|c|}{ Control group } \\
\hline Total & $22.12 \pm 5.47^{1}$ & $16.00^{2}$ & 40.00 & 44.00 \\
\hline 우 & $23.77 \pm 3.52^{3}$ & - & 53.85 & 46.15 \\
\hline$\sigma^{x}$ & $20.33 \pm 6.72$ & 33.33 & 25.00 & 41.67 \\
\hline$p$-value & & & & \\
\hline
\end{tabular}

I $p=0.08$ : study group vs control group; ${ }^{2} p<0.05$ : study group vs control group; ${ }^{3} p=0.09$ : $q$ study group vs $\%$ control group; ${ }^{4} p<0.05$ : A vs B; $\mathrm{SD}$ - standard deviation; HD - hemodialysis; Tx - kidney transplantation.

the difference was not statistically significant. Employment was reported by $46.7 \%$ of the respondents at the mean age of 29.96 \pm 6.9 years (range 20.1-45.1 years). Among those who did not work, $37.5 \%$ of the respondents at the mean age of $18.92 \pm 2.23$ years were still studying.

Among 37 patients after kidney transplantation, 51.4\% reported employment, $24.3 \%$ were still studying and $24.3 \%$ neither worked nor studied. Among 8 patients treated with HD, 2 (25\%) were professionally active and 6 (75\%) did not work. The unemployment rate was significantly higher $(\mathrm{p}<0.01)$ among patients treated with HD compared to those living with a transplanted kidney.

Among 45 respondents, 30 (66.7\%) received social security benefits due to incapacity to work, significantly more commonly ( $\mathrm{p}<0.01$ ) those in whom RRT was initiated in 1973-1992 vs 1993-2007 but with no difference in relation to gender. Social security benefits were received by $56.7 \%$ of the respondents after kidney transplant compared to $87.5 \%$ of the respondent treated with HD, a nonsignificant difference.

Among the respondents, women were significantly more likely $(\mathrm{p}<0.05)$ to start a family. Four respondents $(9.9 \%)$ reported having children, including 3 women and 1 man. Eighty-eight percent of men and $58.82 \%$ of women still lived with their parents. Among the respondents aged $\geq 25$ years, $34.5 \%$ lived independently or with their families, including $63.6 \%$ of women and $16.7 \%$ men. No significant differences in the mean age at the time of the diagnosis of CKD, age at the time of RRT initiation, and duration of dialysis therapy before adulthood were found between the respondents living independently or still with their parents.

\section{Disease acceptance, satisfaction with life and quality of life}

Among the respondents, 28.9\% reported high DA, and $26.7 \%$ of the respondents reported low DA, with no significant differences in relation to gender, period of RRT initiation and the current RRT modality. Patients living in rural areas reported significantly lower $(\mathrm{p}<0.05)$ DA compared to those living in urban areas (AIS score $26.23 \pm 6.52$ vs $31.10 \pm 7.81$, respectively). The lowest scored item was the statement "I will never be self-reliant to the degree I would like to be" (mean score $3.07 \pm 1.69$ ).

A comparison of SWLS scores in the study and control groups is found in Table 3. Low satisfaction with life was reported significantly more frequently $(\mathrm{p}<0.05)$ by the respondents in the study group compared to the control group. Good satisfaction with life was reported significantly more frequently $(\mathrm{p}<0.05)$ by patients with RRT initiated in 1993-2007 compared to those in whom RRT was initiated in 1973-1992. We showed a positive correlation between the age at the time of the diagnosis of CKD and current satisfaction with life $(\mathrm{r}=0.33, \mathrm{p}<0.05)$ (Fig. 1). Patients living in urban areas reported significantly better ( $\mathrm{p}<0.05)$ satisfaction with life (mean score $20.66 \pm 6.31$ ) compared to those who lived in rural areas (mean score $16.85 \pm 3.95)$. Significantly lower $(p<0.05)$ satisfaction with life and DA was reported by those who received social security benefits due to incapacity to work compared to those who did not $(25.3 \pm 5.3$ vs $17.96 \pm 5.15)$. No significant differences in SWLS and AIS scores were found in relation to education, marital status, professional status, and the presence of concomitant diseases. A positive correlation was found between AIS and SWLS scores $(r=0.56$, $\mathrm{p}<0.0001$ ) (Fig. 2).

Results for specific items of the KDQOL questionnaire in patients with ESRD are illustrated on a graph (Fig. 3). Lowest values were obtained for general health perception and work status. Patient satisfaction was assessed low

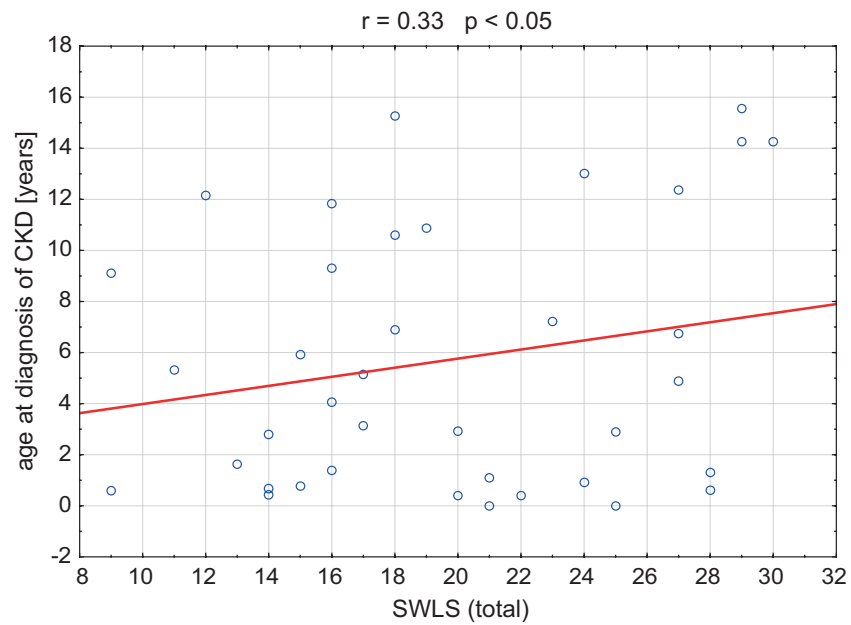

Fig. 1. Correlation between age of the diagnosis of chronic kidney disease (CKD) and results of Satisfaction with Life Scale (SWLS) 


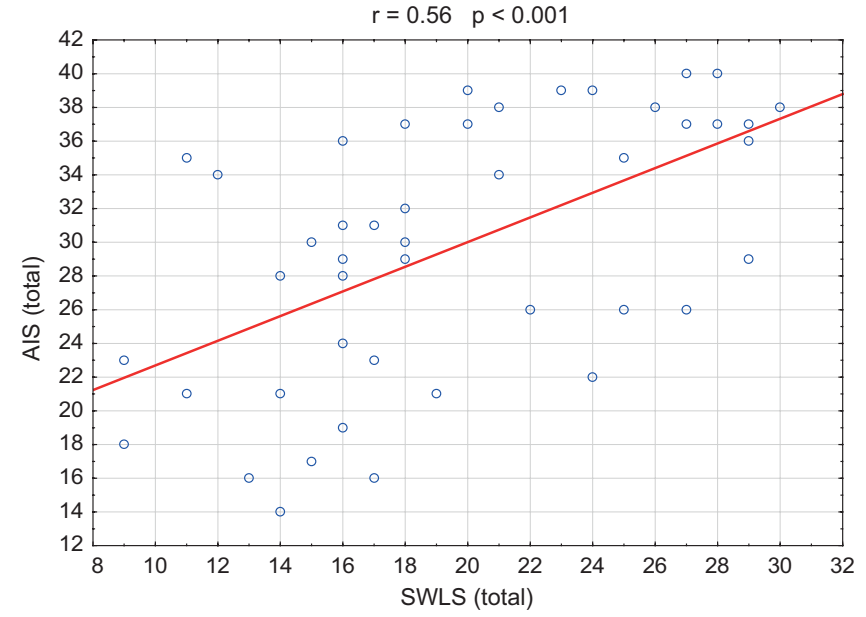

Fig. 2. Correlation between results of Acceptance of IIIness Scale (AIS) and Satisfaction with Life Scale (SWLS)

in the group of patients who started RRT between 1973 and 1992, but the difference in comparison to group B was not statistically significant. The KDQOL scores of patients in whom RRT was initiated in 1993-2007 were significantly higher $(\mathrm{p}<0.05)$ compared to those of patients who started RRT in 1973-1992 in regard to general health perception ( $59.82 \pm 18.05$ vs $44.57 \pm 18.40)$ and dialysis staff encouragement $(83.33 \pm 17.13$ vs $63.75 \pm 15.84)$. No significant differences in physical and emotional components of QOL were found between groups A and B and between women and men. The KDQOL questionnaire results in patients living in rural areas indicated significantly higher $(\mathrm{p}<0.05)$ disease-related burden and lower emotional well-being compared to patients living in urban areas. The KDQOL questionnaire results were not related to receiving social security benefits. We found that the physical component of QOL was significantly worse $(\mathrm{p}<0.05)$ among the respondents who reported primary education compared to those who reported secondary or vocational education.

We found negative correlations between the duration of treatment with HD and the physical functioning component of KDQOL, and between the number of kidney transplantation and the emotional component of QOL $(\mathrm{r}=-0.66, \mathrm{p}<0.05)$ and emotional well-being $(\mathrm{r}=-0.73$, $\mathrm{p}<0.05)$. The time since the last change of RRT modality correlated positively with emotional well-being in our study group $(\mathrm{r}=0.34, \mathrm{p}<0.05)$. No correlations were found
A) KDQOL - general health

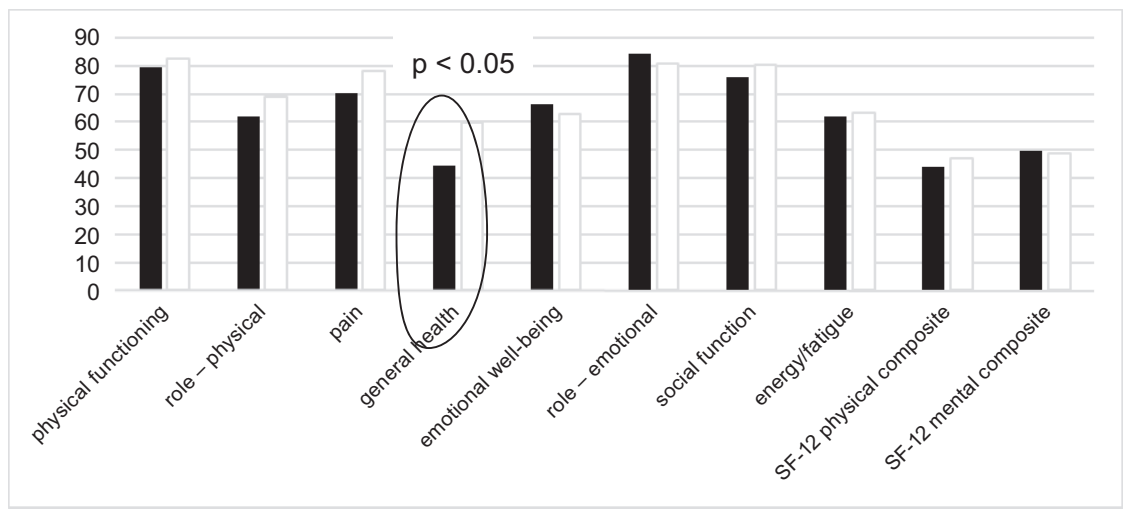

B) KDQOL - kidney disease

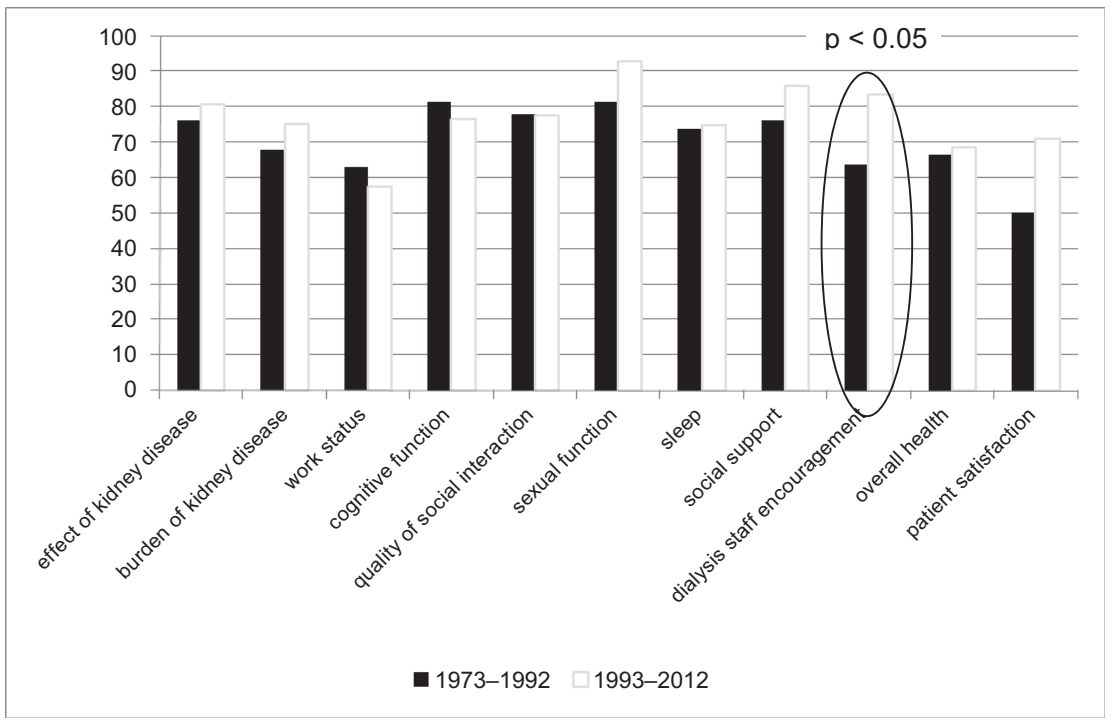

Fig. 3. Results of Kidney Disease Quality of Life (KDQOL) questionnaire - comparison of patients entering RRT between 1973-1992 and 1993-2012: A) KDQOL - general health; B) KDQOL - kidney disease 
between KDQOL questionnaire results and the current age of the respondents, the age at the time of RRT initiation, overall duration of living with a transplanted kidney, and the number of RRT modality changes.

\section{Discussion}

\section{Life activity}

Based on our findings, patients treated with RRT since childhood seem quite well adapted to their chronic disease but showed less ability to live independently compared to the general population, as few of them were professionally active and started their own families, while many continued to live as adults with their parents.

The educational profile of our patients treated with RRT since childhood was similar to that reported for the general Polish population (higher education reported by $18.2 \%$ of our patients compared to $16.5 \%$ in the general Polish population of working age; secondary education reported by $63.6 \%$ and $58.8 \%$, respectively). ${ }^{9}$ These results in our study group are similar to those reported by European patients, with $11-18 \%$ of them reporting higher education and about $1 / 3$ reporting vocational education in the study evaluating the level of education among young Europeans treated with RRT since childhood. ${ }^{10}$ However, a major problem identified in our study group was the unemployment rate (53.3\%), which was about $10 \%$ higher compared to the general Polish population of working age. ${ }^{9}$ Similarly, Groothoff et al. found the unemployment rate among patients treated with RRT since childhood to be twice as high compared to the general population. ${ }^{6}$ In contrast, full- or part-time employment was reported by $70-84 \%$ of the patients treated with RRT since childhood in the USA, ${ }^{11,12}$ and $67.4 \%$ of such patients in the Netherlands. ${ }^{6}$ It has also been reported that the proportion of professionally active subjects among those treated with RRT since childhood continues to grow with each decade. ${ }^{5,10,11}$ In a German study, the proportion of professionally active subjects among patients in whom RRT was initiated in 1970-1984 was 39\% compared to $62 \%$ among those with RRT initiated in 1985-1994. ${ }^{13}$ In our group of patients treated with RRT since childhood, we did not find a significant difference in the proportion of professionally active subjects depending on the decade of initiation of RRT (group A 1973-1992 vs group B 1993-2007). This likely resulted from a $50 \%$ proportion of patients continuing their studies among those in whom RRT was initiated in 1993-2007. In the future they will hopefully increase the rate of professionally active.

Compared to the general population, our patients were much less likely to start their own families. According to the national census data for Poland, $47.89 \%$ of the population aged $15-44$ years is married (51.97\% of women and $57.89 \%$ of men), ${ }^{9}$ compared to $17.8 \%$ in our study group
(35\% of women and 4\% of men). Similarly, in a 1992 European study that included patients aged 21-35 years treated with RRT since childhood, only $13.5 \%$ were married and $8 \%$ had children. ${ }^{13}$ In an American study by Bartosh et al. who evaluated patients after kidney transplantation in childhood, $48 \%$ started their own families and $28 \%$ had children. ${ }^{12}$ Similarly to our study group, other authors also reported that men with ESRD had more difficulties with finding a life partner compared to women, ${ }^{6,14}$ which may be related to social beliefs (men are perceived as those who should provide primary financial support for the family) and physical factors.

Our patients often (76\%) continued to live with their parents after reaching adulthood, which is consistent with the results reported in other studies on the population treated with RRT since childhood. In a Dutch study, 34\% of patients aged $29.3 \pm 5.4$ years continued to live with their parents. ${ }^{6}$ This may be related to financial factors (high unemployment rate, low social security benefits, difficulties with obtaining loans) and social characteristics (low level of independence, lack of social support).

\section{Disease acceptance}

Compared to the general Polish adult population of dialyzed patients, we found better AIS scores in our study group $(25.32 \pm 6.03$ vs $29.7 \pm 7.7),{ }^{8}$ which might have been affected by an earlier disease onset in our respondents and a large proportion of subjects after kidney transplantation, which significantly reduces disease-related burden. Better DA following kidney transplantation compared to dialyzed patients was reported previously. ${ }^{15}$ In another Polish study, lower AIS scores were reported in both patients treated with HD and those treated with PD $(24.53 \pm 1.86$ and $24.24 \pm 2.20$, respectively). ${ }^{16}$ The lowest scored AIS item in the study group was the statement "I will never be self-reliant to the degree I would like to be" which correlated positively with the emotional component of QOL in the KDQOL questionnaire $(\mathrm{r}=0.47, \mathrm{p}<0.01)$ and was scored much lower compared to the reference population of adult dialyzed patients $(3.81 \pm 1.51)$. This result highlights the burden of disease-related limitations, which prevent patients to participate in life as actively as they would like to, and attests to the importance of perceived independence in the assessment of QOL by young people treated with RRT.

\section{Satisfaction with life and quality of life}

In our study group, we found a trend $(\mathrm{p}=0.08)$ towards lower satisfaction with life among patients treated with RRT compared to the control group. In addition, low satisfaction with life was reported significantly more frequently compared to the control group. The mean SWLS score was similar to that reported by Juczyński in adult dialyzed patients $(19.51 \pm 4.65) .{ }^{7}$ Lower satisfaction with 
life compared to healthy peers was also shown by Rosenkranz et al. ${ }^{5}$

When comparing KDQOL scores in our study group with the results reported in a group of adult patients treated with HD in the European DOPPS study, ${ }^{17}$ physical and emotional components of QOL were rated about 10 points higher by men in our study group, while women rated the physical component also about 10 points higher but their rating of the emotional component was similar to the abovementioned European study. However, these findings might have been affected by the type of RRT modality used, as shown in other studies. ${ }^{15,18-20}$ In our study group, the total duration of dialysis therapy, including HD and $\mathrm{PD}$, and the duration of living with a kidney transplant had no effect on the overall rating of QOL, satisfaction with life and DA. Other studies on the effect of RRT duration and modality on QOL in patients with ESRD yielded inconsistent results. British and Italian studies showed a negative effect of the duration of dialysis therapy on QOL. ${ }^{21,22}$ In the study by Rosenkranz et al., no association was found between either total duration of RRT or duration of treatment with specific RRT modalities and satisfaction with life, but the latter was found to be positively affected by the time since successful kidney transplantation. ${ }^{5}$

The lowest values among domains of KDQOL questionnaire were obtained for general health perception and the group of patients who started RRT between 1973 and 1992 had statistically significant lower results. In another Polish study evaluating HRQOL of 69 adult patients with ESRD (44 patients on HD, mean age 49 years, and 25 on PD, mean age 42 years) before and 12 months after kidney transplantation, mean result of KDQOL domain "general health" was 34 points in patients on HD and 32 points in patients on PD which is lower in comparison to our study group. After kidney transplantation KDQOL mean scores in domain "general health" were 40 points (regardless previous RRT method) - similar as in group A in our study group, but lower than in group $\mathrm{B} .{ }^{23}$ Similar result in our group A may be connected with comparable total time of RRT, but the younger age of patients in our group B and shorter time of RRT, may contribute in less comorbidities, which probably influences better assessment of "general health" in KDQOL questionnaire.

Patient satisfaction and dialysis staff encouragement were assessed significantly lower in the group of patients who started RRT between 1973 and 1992 in comparison to group B (1993-2007). The results achieved by patients from group B were similar to the group of patients on chronic HD or after kidney transplantation in another Polish study. ${ }^{23}$ The difference between group A and B may be a result of improvement in patient support, introduction of educational programs directed to patients with chronic renal failure or shorter time of waiting for kidney transplantation. Currently, goals of treatment in patients with CKD include not only prolongation of life and prevention of complications but also a return to normal peer environment and active, satisfactory life.

We found that the physical component of QOL was significantly worse among the patients who reported primary education compared to those who reported secondary or vocational education. Declining of perceived HRQOL with decreasing health status was reported previously. ${ }^{24,25}$

In our study, significantly worse DA, satisfaction with life and disease-related burden and lower emotional well-being in KDQOL questionnaire were found among patients living in rural areas compared to those living in urban areas. Lower chronic DA reported by patients living in rural areas was shown by Niedzielski et al. ${ }^{26}$ Worse DA and adaptation to the burden of chronic disease in patients living in rural areas may be the result of more difficult access to health and social services, support groups and educational programs in comparison to patients living in urban areas. Rural areas have also a higher level of unemployment and poverty, which directly results in a less convenient life and worse emotional well-being. Zagozdzon at al. showed that rural residence was a strong determinant of health-related QOL of Polish females. ${ }^{27}$ They showed that rural residence was positively associated with mental health but negatively with the physical HRQOL. ${ }^{27}$ Significantly worse $(\mathrm{p}<0.05)$ satisfaction with life and DA was found in our study among patients who received social security benefits due to incapacity to work compared to those who did not. In contrast, no association was seen between employment and QOL. In other studies, unemployment was found to be associated with poorer QOL in patients treated with RRT. 6,17,28

In our study group, longer time since the last change of RRT modality correlated positively with emotional wellbeing. Similarly higher number of kidney transplantations (experience of the loss of transplanted organ function) was associated with significantly worse emotional component of QOL and emotional well-being. Such observation is similar to the results described by Griva et al., who showed that the fear of losing transplanted organ function is associated with a significantly worse QOL among patients after kidney transplantation. ${ }^{29}$

In summary, our findings may offer guidance for pediatric nephrologists, who should pay due attention to the appropriate social development and independence of children with ESRD, and inform parents about the importance of their children's appropriate social development and interactions with peers. Results of this study indicate a serious need to create therapeutic teams that would include a psychologist and a social worker.

\section{References}

1. Heijmans M, Rijken M, Foets M, de Ridder D, Schreurs K, Bensingt J. The stress of being chronically ill: From disease-specific to task-specific aspects. J Behav Med. 2004;27(3):255-271.

2. Kalantar-Zadeh K, Kopple JD, Block G, Block G, Humphreys MH. Association among SF-36 quality of life measures and nutrition, hospitalization and mortality in hemodialysis. J Am Soc Nephrol. 2001;12(12): 2797-2806. 
3. Mapes DL, Lopes AA, Satayathum S, et al. Health-related quality of life as a predictor of mortality and hospitalization: The Dialysis Outcomes and Practice Patterns Study (DOPPS). Kidney Int. 2003;64(1):339-349.

4. Bocheńska M, Bednorz R, Niezbrzycka-Andrzejewska K, Wikiera I, Morawska Z. Psychological aspects of the treatment of children with terminal renal failure by repeated hemodialysis [in Polish]. Wiad Lek. 1992;45(1-2):28-31.

5. Rosenkranz J, Reichwald-Klugger E, Oh J, Turzer M, Mehls O, Schaefer F. Psychosocial rehabilitation and satisfaction with life in adults with childhood onset of end-stage renal disease. Pediatr Nephrol. 2005;20(9):1288-1294.

6. Groothoff JW, Groothenhuis MA, Offringa M, Stronks K, Hutten GJ, Heymans HS. Social consequences in adult life of end-stage renal disease in childhood. J Pediatr. 2005;146(4):512-517.

7. Juczyński Z. Narzędzia pomiaru w promocji i psychologii zdrowia. Pracownia Testów Psychologicznych Polskiego Towarzystwa Psychologicznego, Warsaw 2001. [in Polish]

8. Hays RD, Kallich JD, Mapes DL, Coons SJ, Amin N, Carter WB. Kidney Disease Quality of Life Short Form (KDQOL-SFTM), Version 1.2. A Manual for Use and Scoring. Rand Santa Monica. CA, University of Arizona 1995 p. 7928

9. Rocznik Demograficzny Polski 2010, Zakład Wydawnictw Statystycznych, Główny Urząd Statystyczny, Warszawa 2010 p.162-163. https:// stat.gov.pl/obszary-tematyczne/roczniki-statystyczne/roczniki-statystyczne/rocznik-demograficzny-2010,3,4.htm

10. Bulla M, Rosenkranz J. 25 years kidney replacement therapy in childhood and adolescence success of somatic and psychosocial rehabilitation [in German]. Versicherungsmedizin. 1996;48(3):85-89.

11. Potter DE, Najarian J, Belzer F, et al. Long-term results of renal transplantation in children. Kidney Int. 1991;40:752-756.

12. Bartosh SM, Leverson G, Robillard D, Sollinger HW. Long-term outcomes in pediatric renal transplant recipients who survive into adulthood. Transplantation. 2003;76(8):1195-2000.

13. Rizzoni G, Ehrich JHH, Broyer M, et al. Rehabilitation of young adults during renal replacement therapy in Europe. 2. Schooling, employment and social situation. Nephrol Dial Transplant. 1992;7(7):579-586.

14. Kärrfelt HME, Berg UB. Long-term psychosocial outcome after renal transplantation during childhood. Pediatr Transplant. 2008;12(5): 557-562.

15. Keogh AM, Feehally J. A quantitative study comparing adjustment and acceptance of illness in adults on renal replacement therapy. ANNA J. 1999;26(5):471-417.
16. Wlazło A, Kleszczyński J, Makulska I, et al. Psychological factors versus the choice of a renal replacement therapy for patients with chronic renal insufficiency. Nephrol Dial Pol. 2008;12:221-225.

17. Lopes AA, Bragg-Gresham JL, Goodkin DA, et al. Factors associated with health-related quality of life among hemodialysis patients in DOPPS. Qual Life Res. 2007;16(4):545-555.

18. Groothoff JW, Grootenhuis M, Offringa M, et al. Quality of life in adults with end-stage renal disease since childhood is only partially impaired. Nephrol Dial Transplant. 2003;18:310-317.

19. Lanreneau K, Lee K, Landreneau MD. Quality of life in patients undergoing hemodialysis and renal transplantation: A meta-analytic study. Nephrol Nurs J. 2010;37(1):37-34.

20. Muehrer RJ, Becker BN. Life after transplantation. New transitions in quality of life and psychological distress. Semin Dial. 2005;18(2): 124-131.

21. Bakewell AB, Higgins RM, Edmunds ME. Quality of life in peritoneal dialysis patients: A decline over time and association with clinical outcomes. Kidney Int. 2002;61(1):239-248.

22. Baiardi F, Degli Esposti E, Cocchi R, et al. Effects of clinical and individual variables on quality of life in chronic renal failure patients. J Nephrol. 2002;15(1):61-67.

23. Kostro JZ, Hellmann A, Kobiela J, et al. Quality of life after kidney transplantation: A prospective study. Transplant Proc. 2016;48(1):50-54.

24. Mielck A. Vogelmann M, Leidl R. Health related quality of life and socioeconomic status: Inequalities among adults with a chronic disease. Health Qual Life Outcomes. 2014;12:58-67.

25. Gentile S, Beauger D, Speyer E, et al. Factors associated with healthrelated quality of life in renal transplant recipients: Results of a national survey in France. Health Qual Life Outcomes. 2013;11:88-100.

26. Niedzielski A, Humeniuk E, Błaziak P, Fedoruk D. The level of approval in selected chronic diseases [in Polish]. Wiad Lek. 2007;60(5-6): 224-227.

27. Zagozdzon P, Kolarzyk E, Marcinkowski JT. Quality of life and rural place of residence in Polish women: Population-based study. Ann Agricult Env Med. 2011;18(2):429-432.

28. Rutkowski B, Nowaczyk R, Mierzicki P, et al. Quality of care vs quality of life in hemodialysis centers in Poland in the year 2005. Part III. Quality of life [in Polish]. Nephrol Dial Pol. 2008;12:149-155.

29. Griva K, Stygall J, Ng JH, Davenport A, Harrison MJ, Newman S. Prospective changes in health-related quality of life and emotional outcomes in kidney transplantation over 6 years. J Transplant. 2011;2011:671571. 